\title{
Research of hydration heat of Portland cement used in bridge construction of Kerch Strait
}

\author{
Sergey Pulyaev ${ }^{1}$, Ivan Pulyaev ${ }^{1}$, Vasily Korovyakov ${ }^{2}$ and Anatoliy Sitkin ${ }^{1}$ \\ ${ }^{1}$ Moscow State University of Civil Engineering, Yaroslavskoe shosse, 26, Moscow, 129337, Russia \\ ${ }^{2}$ Research Institute Mosstroy,105066, Moscow, Russia
}

\begin{abstract}
The article discusses issues related to the study of heat generation of cements used in the construction of a bridge across the Kerch Strait. This problem seems to be important because of the construction of the mentioned object in conditions of a dry hot climate. The study was conducted with the use of modern information and analytical systems in real time, allowing obtaining results close to real conditions. On the basis of comparative analysis of the calculation and practical measurement of heat the main conclusions of the work were done, recommendations on the use of cements of various types in the construction of the bridge Kerch and other similar extra-curricular facilities that are included in the basis of the developed technological regulations for the production of preparatory, reinforcement, formwork and concrete works in circumstance of yearround construction.
\end{abstract}

\section{Introduction}

In our country the construction of a unique bridge across the Kerch Strait with a length of more than $19 \mathrm{~km}$ began in 2015. The location of the object in salt sea water, increased requirements for seismic resistance, the availability of ice loads, a large height of the structure, a great depth of the strait and other factors require a serious approach to guarantee the quality of concrete work and the durability of the structure. It is known that heat generation affects to the quality of concrete works, the construction time and the durability of structural elements, as a result heat generation determines many technological factors [1]. The experience of construction of dry docks at the shipbuilding facilities "Zaliv" (Kerch) and "Okean" in Nikolaev showed that the heat generation depends on many factors that must be taken into account if you develop the technology of concreting. For a number of years A. Solovyanchik has carried out studies. During research of heat generation of cement based on studying the physical process of cement hydration and generalizing the long-term experiment, the temperature function of the kinetics of cement hydration on the viscosity of the mixing water was obtained.

\section{Materials and methods}

The study of the heat generation of cements was carried out according to a specially developed technique proposed by [2,3]. When studying the influence of concreting 
conditions on the heat emission of cement, sulfate-resistant cement was used at the NovoAmvrosievsky plant, with a mineralogical composition of C3S of $45 \%, \mathrm{C} 2 \mathrm{~S}$ of $35 \%, \mathrm{C} 3 \mathrm{~A}$ of $3.5 \%$, and $\mathrm{C} 4 \mathrm{AF}$ of $13 \%$. The concrete mixture had the following consumption of materials per one cubic meter of concrete: cement M400 - $280 \mathrm{~kg}$, sand - $630 \mathrm{~kg}$, rubble fr. $5-20 \mathrm{~mm}-458 \mathrm{~kg}$, crushed stone fr. $20-40 \mathrm{~mm}-392 \mathrm{~kg}$, crushed stone fr. $40-70 \mathrm{~mm}-457$ $\mathrm{kg}$, water - 134 liters. When the concrete was closed, additives were used (in $\%$ of the weight of the cement): SNV-P $0.002 \%$; KDT $-0.07 \%$. The processing of the experimental data was carried out using a PC. For the reliability of the results obtained, each experiment was repeated 2-3 times.

The heat generation of cement of the following compositions was also determined in a thermosensitive calorimeter: cement test with $\mathrm{V} / \mathrm{C}=0.3$, placed in the device immediately after the cement has been mixed with water and mixing; concrete, prepared in a concrete mixer directly on the building and placed immediately after manufacturing in the device; concrete of the same composition, prepared in a concrete mixer, vibrated immediately after manufacture and laid in the device; the same concrete, but vibrated after 30-35 minutes after preparation and then placed in the device.

As follows from the analysis of the integral heat dissipation curves (Fig. 1), the concreting conditions have a significant effect on the heat generation of cement at the initial time of hardening of concrete. In the first 3-5 days, the least heat generation is observed when testing the cement test, slightly more for concrete laid without vibration and vibrating immediately after manufacture, and even more for concrete, vibrated after 30-35 minutes after preparation.

The increase in the heat generation of cement when it is hardened in concrete without vibration as compared to the heat generation of the cement paste can be explained by the fact that inert aggregates, when the concrete mix is mixed in a concrete mixer, move the cohesive cement grains, deform and break them, providing free water access to more grains than when hardening cement paste without aggregates. Increase in the number of cement grains taking part in the hydration reaction, i.e. an increase in the reaction surface, facilitates the acceleration of the hardening of concrete at a young age due to an increase in the yield of hydration products. The increase in the amount of hydration products is accompanied by an increase in the amount of heat released.

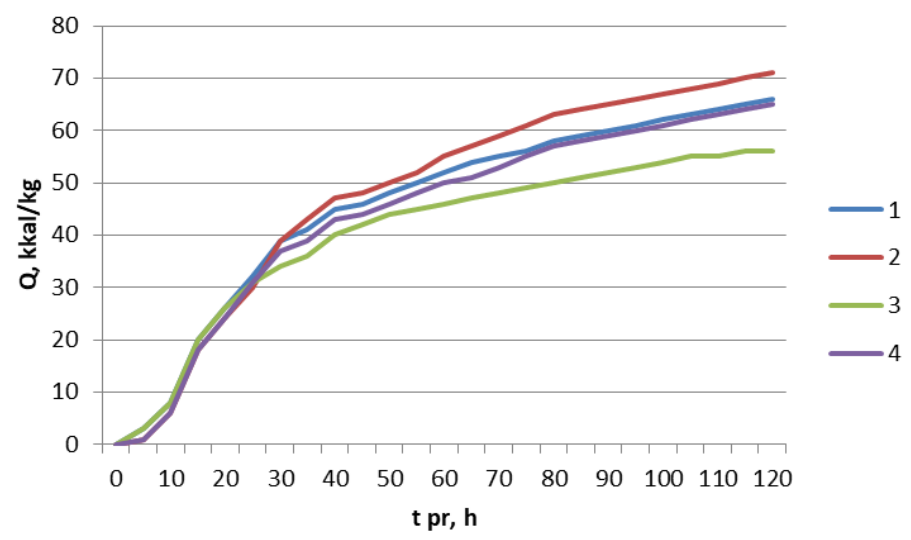

Fig.1. Heat generation of cement: 1 - in concrete, vibrated immediately after mixing; 2 - in concrete, vibrated after 35 minutes after kneading in a concrete mixer; 3 - cement paste on distilled water; 4 - in the vibrated concrete 
The experiments showed that the concreting conditions significantly influence the character of the change in time of all types of heat and for the time required to equalize their absolute values.

Studies have shown that vibrating concrete after 30-35 minutes after the preparation of the concrete mix leads to a significantly greater decrease in the temperature of the samples under study and to a delay in the beginning of the rise in temperature. However, the subsequent rise in the temperature of the samples occurs at this more intensively than the rise in temperature of the samples from the cement dough and concrete, vibrated immediately after manufacture. The physical essence of this phenomenon is the following. When hydrating cement, the surface of the grains is covered with water, and they begin to dissolve intensively. After saturation of the solution around the grains, films of new formations appear that make hydration not selective, but due to diffusion processes through them and the boundary layer into the grain surface. The hydration products are deposited in the boundary layer, in the film of the tumors, and are taken out into the pores filled with water.

The rate of structure formation during hydration of cement, and, consequently, the heat generation rate is limited by the difference in the concentrations of the initial (cement and water) and final (new formations) products, and diffusion of water and intermediate products through the boundary layer and neoplasms. Determining the rate of hydration, and, consequently, the rate of heat generation during the reaction of hydration of cement as a heterogeneous reaction at temperatures above $20-25{ }^{\circ} \mathrm{C}$ are diffusion processes. When the concrete is shaken after 30-35 minutes (or somewhat later), the new formations and reaction shells covering the cement grains are destroyed, which ensures free access of water to the unreacted surface of the cement grains. Secondary the intensive dissolution of cement grains begins, reducing for a while the temperature of the sample due to the predominance of the endothermic dissolution process over exothermic processes. However, in the case under consideration, the degree of hydration of cement grains in a short time is significantly increased, which leads to a significant increase in the yield of hydration products, and is accompanied by an increase in the amount of heat released by $10-20 \%$ in the early periods of hardening of concrete.

It should be noted that delayed vibration along with an increase in the integral isothermal heat generation increases the brand strength of concrete. This can also be explained by an increase in the degree of hydration of cement grains.

Investigations established that the time of the greatest intensity of heat generation of cement corresponds to the time of formation of the spatial crystallization structure in the cement stone, i.e. time of transition of a concrete mix in concrete. Analysis of the intensity of heat generation under various conditions of concreting showed that with delayed concreting the time of formation of the concrete under study as a material takes place at 7 hours of the given time (the time of hardening of concrete under isothermal conditions at a temperature of $15^{\circ} \mathrm{C}$ ) earlier than in the cement test and 4-5 hours earlier, than in concrete, vibrated immediately after manufacture.

To study the degree of influence of chemical additives on the heat emission of cement during hardening of concrete, the heat generation of a cement test, sealed with distilled water, tap water, water with an additive of $2.5 \%$ by weight of $\mathrm{CaCl}_{2}$ cement, tap water with SNV-P and KDT additives was studied. The results of the experiments are given in Figure 2. 


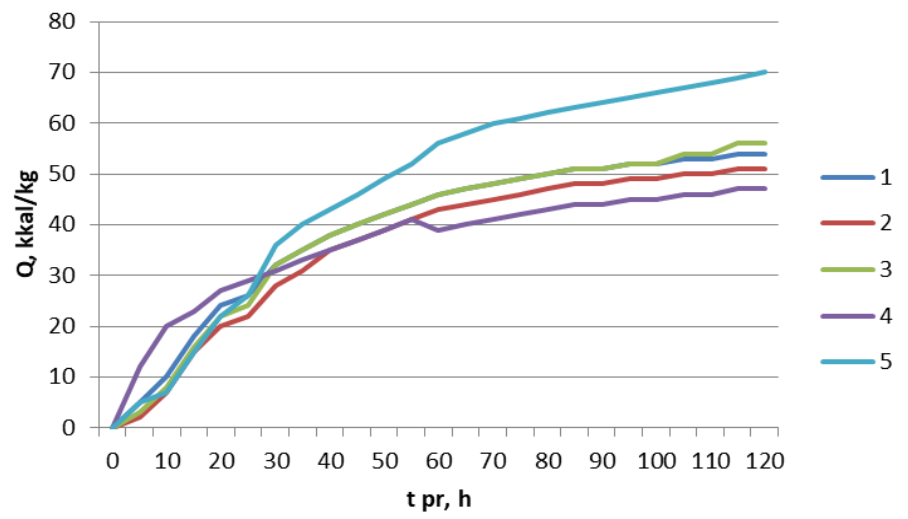

Fig.2. Heat generation of cement paste, 1 - on distilled water; 2 - in city water; 3 - the same, but with additions of START-II and KDT; 4 - the same, but with addition of $2.5 \% \mathrm{CaCl}_{2}: 5$ heat generation of real concrete

The introduction of calcium chloride in an amount of $2.5 \%$ of the weight of the cement contributed to the increase in the amount of heat released in the initial period of hardening the solution (up to 20-22 hours), and to some decrease in the amount of heat released when the solution is hardened at a later date (hereinafter the comparison with heat generation of cement, sealed with distilled water). The data obtained agree with the data on the increase in the strength of concrete with an additive of $2.5 \% \mathrm{CaCl}_{2}$, where a decrease in the build-up of strength at later hardening times is also observed.

Proceeding from this, it can be concluded that when the cement is closed with an aqueous solution of $\mathrm{CaCl}_{2}$ electrolyte, conditions are created for increasing the dissolution rate of the aluminates, the effect of which also has a significant effect on the first day of hydration of the cement.

Cement, closed on tap water containing various mineral impurities, the main one of which is $\mathrm{CaCl}_{2}$, gave out in the initial period of hardening a somewhat smaller amount of heat than cement with an additive of $2.5 \% \mathrm{CaCl}_{2}$. However, after 30 hours of cement hardening in tap water, the amount of heat released exceeded the heat generation from $2.5 \%$ of $\mathrm{CaCl}_{2}$ and on the fifth day of hardening was leveled with the amount of heat released by the cement, which was closed on distilled water.

As the cement arrived at the construction site, having a temperature of up to $50-110{ }^{\circ} \mathrm{C}$, the heat emission of cement having a temperature of $+75^{\circ} \mathrm{C}$ was investigated. Analysis of the data given in Fig. 3 shows that the high temperature of cement sharply (by 1.5 - 2 times) raises the integral isothermal heat generation of cement. This phenomenon can be explained by the fact that hot steam has not yet had time to come in contact with water vapor contained in the air, and create a protective film of growths that protects the cement in the future from intensive hydration while blocking with astringent water. Due to the fact that numerous microcracks and pores are formed during the firing of the clinker, the cement grains have an increased free surface on which the hydration reaction can take place. When wetting such cement grains with water, a large number of hydration products are formed in short intervals, an intense structuring begins, accompanied by intense heat generation $[4,5]$. 


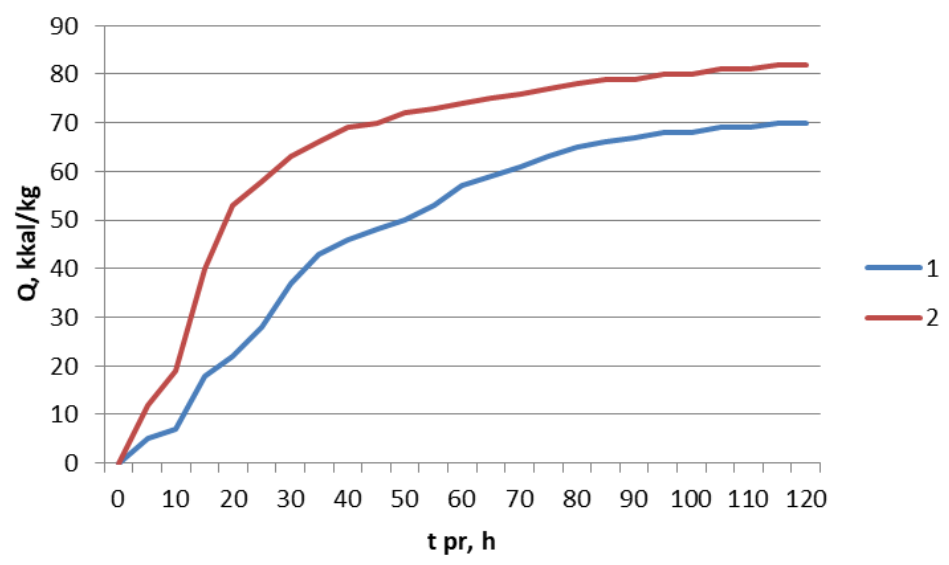

Fig.3. Heat generation: 1 - cement in concrete, vibrated after 35 minutes after making; 2 - cement paste made from cement, which have a temperature of $75^{\circ} \mathrm{C}$

In the absence of experimental data, the heat generation of concrete in thermal calculations is usually determined based on the mineralogical composition of the cement used to prepare concrete $[6,7,8]$. Analysis of the experimental curves of the integral heat generation (Figure 4) showed that the heat generation of concrete laid in the construction is much higher than the heat generation of concrete, which was determined on the basis of the mineralogical composition of sulfate-resistant Portland cement, which needed to be taken into account when selecting the concrete mixes used in the construction of the Kerch bridge.

Studies have also shown that to obtain additional data on heat generation, it is necessary to investigate the actual compositions used. In this connection, it became necessary to determine the heat emission of cements produced in Novorossiysk Cement Plant, one of the main suppliers of cement for the construction of the Kerch bridge.

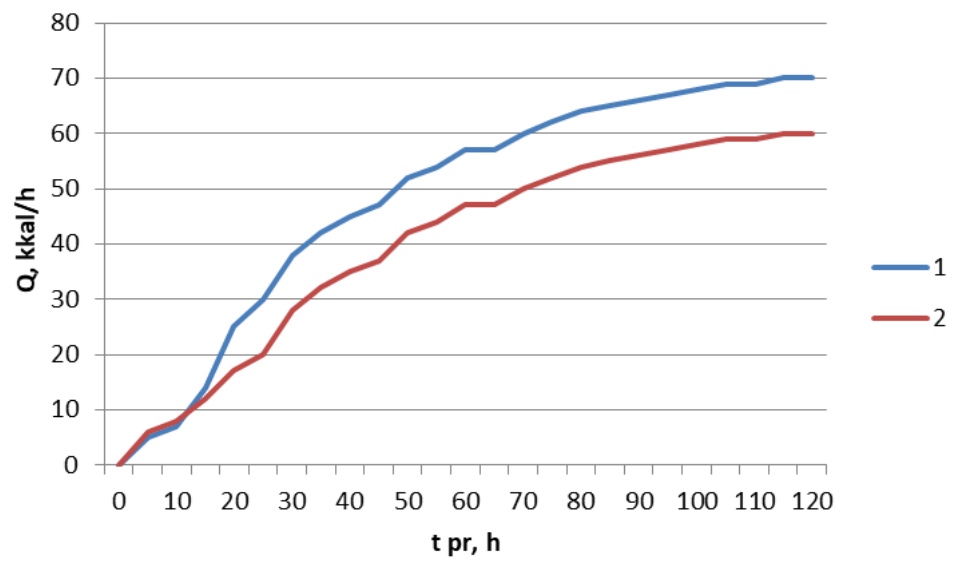

Fig.4. Heat generation of concrete: 1 - vibrated after 35 minutes after mixing; 2 - calculated by mineralogical composition.

The heat generation was determined by the method of solving the inverse problem [9, 10]. For this purpose, two formwork forms were prepared from plywood $18 \mathrm{~mm}$ thick with insulation from two layers of foam plastic to $30 \mathrm{~mm}$ each. Inside each form was installed 
reinforcing bar with attached to it thermocouples connected to the receiving device. In the factory, mixes of a concrete mixture of class B45 on Portland cement without mineral additives, type CEM I class 42.5 and on sulphate-resistant cement type CEM 1 class 42.5 BSS were manufactured. In the preparation of mixtures, sand was used with Mcr in the rate of 2.84; rubble fraction 5-20 $\mathrm{mm}$ and plasticizing additive - Glenium 591. The mobility of the concrete mixture on Portland cement without mineral additives was $18-20 \mathrm{~cm}$, on sulphate-resistant cement $-12-15 \mathrm{~cm}$ cone sediments. The room temperature was $20{ }^{\circ} \mathrm{C}$, humidity $-56 \%$. After laying the concrete mixture in the formwork, its exposed surface was covered with polyethylene film and dornite, a record of the thermocouple readings, which was carried out for seven days, was included.

\section{Results and discussions}

The results of measuring the temperatures of the hardening concrete and the temperature in the room are following. The maximum heating of the sample on Portland cement without mineral additives was $8.5{ }^{\circ} \mathrm{C}$ higher than that of the sample on sulphate-resistant cement. Experience has shown that the concrete on the additive cement is heated much more than on sulfate-resistant cement. Strength of concrete on the seventh day was: for concrete class B45 made with Portland cement without mineral additives, type CEM I class 42.5 - 62.57 and $58 \mathrm{MPa}$; for concrete class B45 on sulphate-resistant cement class 42.5 BSS - 54.55 and $51.5 \mathrm{MPa}$.

\section{Conclusion}

The carried out theoretical and experimental studies of the heat generation of cement during hardening in concrete allowed to obtain conclusions:

- delayed vibration of concrete mixture increases the heat emission of cement during hardening in concrete at the initial time of its hardening ( $1 \ldots 2$ days) on average by $6 \ldots 9 \%$ and this change must be taken into account when carrying out thermophysical calculations of temperature and strength conditions and the thermal stress of concrete in structures by introducing a correction factor or actual heat generation data into the calculation program based on the results of field trials;

- based on the tests carried out in a thermosensor calorimeter, it was found that the combined use of complex additives in the amount recommended by regulatory documents to increase the frost resistance of concrete has practically no effect on the heat generation of cement during hardening in concrete $[11,12]$;

- the use of hot cement with a temperature of more than $60{ }^{\circ} \mathrm{C}$, arriving at the construction site from a cement plant, during the preparation of a concrete mixture, increases the heat generation by an average of 1.5 to 2 times the heat dissipation of a concrete mix prepared using cement with a temperature of $15 \ldots 20{ }^{\circ} \mathrm{C}$ massive design);

- the actual heat emission of cement during the curing process in concrete is often higher than the heat dissipation calculated by the mineralogical composition of the cement, on average by $10 \ldots 15 \%$;

- sulfate-resistant cement can be effectively used in the production of works during the hot season in the conditions of intensive construction of the site. It has a lower heat generation relative to the usual Portland cement, because of the reduced content of $\mathrm{C}_{3} \mathrm{~S}$ and $\mathrm{C}_{3} \mathrm{~A}$ cement minerals $[13,14]$. 


\section{References}

1. I. S. Pulyaev, S.M. Pulyaev, Vestnik MGSU, 2 (2011)

2. L. Frølich, L. Wadsö, P. Sandberg, Cem. and Concr. Res., 88 (2016)

3. K. Takahashi, Th. A. Bier, T. Westphal, Cem. and Concr. Res., 41, 11 (2011)

4. K. L. Scrivener, A. Nonat, Cem. and Concr. Res., 41, 7 (2011)

5. A. R. Solovyanchik, I.S. Pulyaev, Vestnik TyumGASU, 4 ( 2015)

6. A. R. Solovyanchik, V.N. Korotin, S.G. Veytsman, I.S. Pulyaev, Vestnik mostostroeniya, 2 (2008)

7. B.M. Krasnovskiy Engineering and physical basis of winter concreting methods, 470 (Moscow, 2002)

8. M. M. Syichev, Hardening of binders (Stroyizdat, St.Petersburg, 1974)

9. A. V. Ginzburg, Vestnik MGSU, 1 (2014)

10. L. Wang, H. Q. Yang, S. H. Zhou, E. Chen, S. W. Tang Constr. and Build. Mat., 187 (2018)

11. V. Rahhal, V. Bonavetti, L. Trusilewicz, C. Pedrajas, R. Talero, Constr. and Build. Mat., 27, 1 (2012)

12. X. Pang, P. Boul, W. Cuello Jimenez, Constr. and Build. Mat., 77 (2015)

13. V. Rahhal, R. Talero, Constr. and Build. Mat., 23, 11 (2009)

14. N. V.Smirnov, E.A. Antonov, The role of concrete creep in the formation of thermal stress state of monolithic reinforced concrete structures in the process of their construction in Proceedings of TsNIIS, 213 (Moscow, 2005) 